\title{
Risk factors for blindness in patients with open-angle glaucoma followed-up for at least 15 years
}

\author{
Fatores de risco para cegueira em pacientes com glaucoma de ângulo aberto acompanhados \\ por pelo menos 15 anos
}

Jayter Silva Paula ${ }^{1}$, João Marcello Furtado ${ }^{1}$, Arles Silva Santos ${ }^{1}$, Roberto de Mattos Coelho ${ }^{1}$, Eduardo Melani Rocha ${ }^{1}$, Maria de Lourdes Veronese Rodrigues ${ }^{1}$

\begin{abstract}
Purpose: To determine the proportion of blindness and investigate the relationships between risk factors based on clinical characteristics and development of blindness in patients with primary open-angle glaucoma (POAG) treated for at least 15 years.

Methods: A retrospective observational chart review was performed with 403 patients referred to a tertiary level hospital, each with a diagnosis of primary openangle glaucoma, treated for at least 15 years. Blindness attributable to glaucoma was defined based on visual acuity and/or visual field tests. Variables considered to be possible risk factors for blindness were evaluated using odds ratio (OR), confidence interval $(95 \% \mathrm{Cl})$, and univariate and multivariate analyses.

Results: Thirty-one patients became blind [13/53 (24.5\%) - unilaterally and 18/53 (34\%) - bilaterally] during the follow-up period of treatment ( $19.5 \pm 4.6$ years, range 15-31 years). Multivariate statistics with regression analysis revealed that persistency on initial therapy $\leq 6$ months was significantly associated with blindness, both unilateral (OR: 8.4; 95\% Cl: 1.3-56.4) and bilateral (OR: 7.2; 95\% Cl: 1.3-39.6). Other potential factors such as race, age, gender or number of medications were not associated with blindness.

Conclusion: Blindness from primary open-angle glaucoma was not uncommon in this population of treated patients after the long follow-up period proposed. Persistence rates with the first therapy, as measured by a medical decision to change, were low. Persistence $\leq 6$ months was statistically associated with the development of unilateral and bilateral blindness from glaucoma.
\end{abstract}

Keywords: Glaucoma, open-angle/complications; Blindness/etiology; Optic disk/physiopathology; Glaucoma, open-angle/therapy; Visual acuity; Risk Factors

\section{RESUMO}

Objetivos: Determinar a frequência de cegueira e investigar a relação entre os fatores de risco, com base nas características clínicas e no desenvolvimento da cegueira, em pacientes com glaucoma primário de ângulo aberto (GPAA) tratados pormais de 15 anos. Métodos: Realizou-se a revisão dos prontuários (estudo retrospectivo, observacional) de 403 pacientes referidos a um hospital de nível terciário, todos com diagnóstico de glaucoma primário de ângulo aberto feito em 1974 ou posteriormente, e tratados por no mínimo 15 anos. Cegueira atribuível ao glaucoma foi definida com base na acuidade visual elou exames de campo visual. Variáveis consideradas possíveis fatores de risco para cegueira (uni ou bilateral) foram avaliados usando odds ratio (OR), intervalo de confiança (IC95\%) e análises uni e multivariadas.

Resultados: Trinta e um pacientes ficaram cegos [13/53 (24,5\%) - um olho cego e 18/53 (34\%) - cegueira bilateral] durante o período de seguimento (19,5 $\pm 4,6$ anos, variando de 15 a 31 anos). Estatística multivariada com análise de regressão mostrou que persistência com a terapia inicial $\leq 6$ meses está significantemente associada com cegueira, unilateral (OR: 8,4;95\% IC: 1,3-56,4) e bilateral (OR: 7,2;95\% IC: 1,3-39,6). Outros potenciais fatores como raça, idade, gênero ou número de medicações não estiveram associados com cegueira.

Conclusão: Cequeira por glaucoma primário de ângulo aberto não foi incomum na população de pacientes tratados e seguidos por um longo período. As taxas de persistência com a terapia inicial, medidas pela decisão médica de mudar o tratamento, foram baixas. Persistência $\leq 6$ meses foi estatisticamente associada com o desenvolvimento de cegueira uni ou bilateral por glaucoma.

Descritores: Glaucoma de ângulo aberto/complicações; Cegueira/etiologia;Discoóptico/fisiopatologia; Glaucoma de ângulo aberto/terapia; Acuidade visual; Fatores de risco

\section{INTRODUCTION}

Glaucoma is a chronic disease and a major cause of blindness, with the control of intraocular pressure (IOP) being the only evidence-based mode of treatment ${ }^{(1-3)}$. Appropriate treatment of glaucoma requires an evaluation of the rate of deterioration of the disease over time. Without some sense of the disease deterioration rate over time it is difficult to determine the real benefits of treatment ${ }^{(1)}$.

Treatment persistency has been defined as total time on a defined therapy, involving not just patient compliance with medical recommendation, but also medical decisions ${ }^{(4,5)}$.

The consequence in primary open-angle glaucoma (POAG) is that longer persistency is also associated with the number of days of controlled IOP(4). Therefore, we must rely on studies that characterize the course of treated glaucoma ${ }^{(6-9)}$.

Although there is available information regarding visual field in long-term treatment glaucoma, other parameters could be added in order to enhance the understanding of the disease, such as the losses in nerve fiber layer and the progression of optic disc abnormalities ${ }^{(4,8-10)}$.

The objective of the study was to investigate the deterioration of visual acuity and visual field, in terms of the development of legal blindness, and to explore the relationship between blindness due to glaucoma and risk factors based on initial clinical findings in POAG patients followed for at least 15 years at a tertiary level hospital in Brazil.
Funding: No specific financial support was available for this study

Disclosure of potential conflicts of interest: J.S.Paula, None; J.M.Furtado, None; A.S.Santos, None; R.M.Coelho, None; E.M.Rocha, None; M.L.V.Rodrigues, None.

Correspondence address: Maria de Lourdes Veronese Rodrigues. Hospital das Clínicas, Oftalmologia - Campus USP - Ribeirão Preto - SP - 14048-900 - Brazil - E-mail: mdlvrodr@fmrp.usp.br 


\section{METHODS}

This is a retrospective comparative study based on chart review of 403 patients referred to the Glaucoma Service - Medical School of Ribeirão Preto University Hospital, in 1974 or later, 103 of them treated for at least 15 years.

Of these 103 medical records, 53 charts fulfilled the inclusion criteria and were included in this study. Mean follow-up period of treatment was $19.5 \pm 4.6$ years (range 15-31 years).

All patients without previous ocular surgery and with an indication of glaucoma therapy were included. We excluded patients who had any eye surgery other than anti-glaucomatous surgery during follow- up, or turned suspect of having other type of glaucoma. The study was conducted according to the Declaration of Helsinki and was approved by the institutional Review Board / Ethics Committee (HCRP nำ2302/2006).

Subjects included in this study $(n=53)$ had optic nerve appearance and/or visual field defects consistent with POAG, and a documented IOP of more than $21 \mathrm{mmHg}$. Optic nerve criteria included a cup-to-disc (C/D) ratio of 0.6 or greater in the vertical dimension, or C/D asymmetry of 0.2 or greater, or notching or thinning of the optic disc rim. Other optic disc changes related to glaucoma were considered to be additional confirmation of glaucoma.

Patients underwent kinetic perimetry using a Goldmann perimeter, or achromatic static automated perimetry (SAP) using either the Humphrey 30-2 or 24-2 full threshold programs (Humphrey-Zeiss Systems, Dublin, CA). Criteria for SAP abnormality required 2 of the following 3 criteria to be met in at least 2 consecutive visual fields ${ }^{(11,12)}$ : (1) an abnormal glaucoma hemifield test; (2) 3 contiguous non-edge points (allowing the 2 nasal step edge points) on a Humphrey program 30-2 full-threshold visual field with a $P$ value $<0.05$ on the total deviation plot, with at least 1 point having a $P$ value $<0.01$; (3) on fullthreshold tests, a corrected pattern standard deviation $P$ value $<0.05$.

Because of the diversity of the visual field examinations methods over the extended follow-up period, a generic grading system was used to grade all glaucomatous field defects: grade 0 - no visual field defect present; grade I - nasal step or localized paracentral defect; grade II - nasal step and paracentral defect or a single arcuate defect; grade III - two arcuate scotomas or an altitudinal scotoma not encroaching on fixation; grade IV - advanced visual field loss with or without fixation loss ${ }^{(13)}$

Patients with ocular diseases that might mislead the interpretation of visual field testing were excluded. If an event occurred during follow-up that precluded further information on blindness from glaucoma, the patient was dropped off from the analysis. In cases in which other causes of visual disability were present in the same patient, the decision was based in the primary cause of blindness on the basis of the data available.

Variables considered as possible risk factors for blindness were: age at diagnosis, race, gender, initial visual acuity, number of antiglaucomatous drugs in use, IOP, optic cup-to-disc ratio and visual field abnormalities, persistency on initial therapy, and number of anti-glaucomatous surgeries.

The duration of persistency of the initial treatment was defined as the period between the first visit and the visit when discontinuation was determined by medical decision (by inclusion, exclusion, or substitution of anti-glaucomatous medication or indication of laser or surgical treatment). Changes in the frequency, commercial name or dosage of the same medication in use were not considered to be persistency failure. Persistency was analyzed considering patients with six months or less on initial therapy in one category, and those with more than six month on initial therapy in another.

Visual acuity was categorized as follows: category I - 20/20 to 20/30; category II - <20/30 to 20/60; category III - <20/60 to 20/200; category IV - <20/200 to counts fingers; category $V$ - counts fingers to no light perception.
Blindness was defined as visual acuity worse than 20/200, and/ or continuous constriction of the visual field to less than $20^{\circ}$ in all four quadrants with a size III4e Goldmann stimulus or the equivalent on automated perimetry, allowing a higher threshold level on one point in one quadrant, attributable to glaucoma ${ }^{(14)}$ in the worst eye (unilateral) or in both eyes.

Based on blindness from glaucoma at the end of follow-up, three groups of POAG patients were compared, using all data collected: Group 1 - Patients presenting VA $\geq 20 / 200$ in both eyes; Group 2 - Patients presenting unilateral blindness; and Group 3 - Patients presenting bilateral blindness. For comparisons purposes, only eyes which became blind, in group 2 and 3, or the worse eye in group 1, were considered.

Data are reported as mean \pm standard deviation or proportions. Statistical analysis included odds ratios (OR), confidence intervals $(95 \% \mathrm{Cl})$, exact Fisher's exact test, unpaired $t$ test and possible risk factors of blindness were studied using a multivariate model of regression analysis with mixed procedures (SAS - version 9, SAS Institute Inc.).

\section{RESULTS}

At the end of follow-up $41.5 \%$ of the 53 patients studied did not present blindness (Group 1, $n=22$ ), 24.5\% presented unilateral blindness (Group 2, $n=13$ ), and 34\% presented bilateral blindness (Group $3, n=18)$. Thirty four (64\%) of 53 patients were females and $19(36 \%)$ were males. The majority of patients $(35 / 53)$ were white and mean age at initial evaluation was $53.2 \pm 11.7$ years.

The initial characteristics of subjects who became blind (Group 2 and 3) or not (Group 1) are shown in table 1.

In the comparison between Groups 1 and 2, univariate analysis of the variables selected as possible risk factors for blindness from POAG revealed that persistency $\leq 6$ months (OR: 7.0; 95\% Cl: 1.2-41.3 - $P=0.013)$ and initial IOP (OR: 1.16; 95\% Cl: 1.01-1.34 - $P=0.024)$ were significantly associated with the development of unilateral blindness. Comparing groups 1 and 3, univariate analysis showed that persistency $\leq 6$ months (OR: 5.3; 95\% Cl: 1.3-21.9 - P=0.025), initial worse visual acuity categories [IV and V] (OR: 13.3; 95\% Cl: 2.2-81.2 - P=0.004) and number of glaucoma surgeries (OR: 1.73; 95\% Cl: 1.01-2.99) were statistically related to bilateral blindness at the end of follow-up.

Multivariate statistics with regression analysis revealed that number of glaucoma surgeries was related only to bilateral blindness (OR: 2.07; 95\% Cl: 1.09-3.92), whereas persistency $\leq 6$ months was associated with the development of unilateral (OR: $8.4 ; 95 \% \mathrm{Cl}: 1.3-56.4$ ) and bilateral (OR: 7.2; 95\% Cl: 1.3-39.6) blindness.

\section{DISCUSSION}

Our study indicates that POAG leads to blindness in a significant number of individuals, even while patients are receiving therapy. After approximately 19 years of follow-up, 31 treated patients became blind either unilaterally (24.5\%) or bilaterally (34\%).

Comparisons with previous studies on blindness from POAG are difficult because of differences in methodology, follow-up, and the populations studied. The systems of disc and field grading used in this study are believed to be more appropriate, since no stereo photography of the optic nerve head was available and, as done in other studies ${ }^{(13,14)}$ we had to consider a categorical manner to analyze different visual field perimeters during the follow-up period.

Even considering the differences, a similar study conducted at a referral hospital ${ }^{(15)}$ with 183 glaucoma patients reported that the estimated risk of unilateral and bilateral blindness at 15 years was $14.6 \%$ and $6.4 \%$, respectively. Another community-based study ${ }^{(7)}$ analyzing 100 patients diagnosed with "classic glaucoma", reported higher percentages of blindness, almost similar to our results (54\% and 22\% for unilateral and bilateral blindness, respectively). Most other treatment 
Table 1. Selected clinical characteristics of patients at presentation and other factors considered to be risk factors for the development of blindness from POAG in patients treated for at least 15 years

\begin{tabular}{|c|c|c|c|}
\hline & \multicolumn{3}{|c|}{ Blindness } \\
\hline & No & Unilateral & Bilateral \\
\hline Age (years) & $51.5 \pm 12.5$ & $51.2 \pm 13.8$ & $56.8 \pm 8.7$ \\
\hline \multicolumn{4}{|l|}{ Race } \\
\hline Black & 3 & 2 & 4 \\
\hline White & 16 & 10 & 9 \\
\hline Other & 3 & 1 & 5 \\
\hline Male: Female proportion & 0.16 & 2.25 & 0.64 \\
\hline \multicolumn{4}{|l|}{ Visual acuity } \\
\hline \multicolumn{4}{|l|}{ Category } \\
\hline 1 & 12 & 6 & 4 \\
\hline$\|$ & 7 & 3 & 3 \\
\hline III & 3 & 4 & 1 \\
\hline IV & 0 & 0 & 3 \\
\hline V & 0 & 0 & 7 \\
\hline Initial IOP\# (mmHg) & $20.7 \pm 4.7$ & $26.2 \pm 9.3$ & $23.9 \pm 7.7$ \\
\hline Anti-glaucomatous drugs & $1.3 \pm 0.5$ & $1.4 \pm 0.5$ & $1.4 \pm 0.6$ \\
\hline Cup-to-disc ratio* & $0.47 \pm 0.23$ & $0.54 \pm 0.32$ & $0.62 \pm 0.25$ \\
\hline \multicolumn{4}{|l|}{ Visual field* } \\
\hline \multicolumn{4}{|l|}{ Grade } \\
\hline 0 & 17 & 5 & 3 \\
\hline । & 4 & 3 & 2 \\
\hline$\|$ & 1 & 1 & 1 \\
\hline III & 0 & 2 & 0 \\
\hline IV & 0 & 0 & 12 \\
\hline \multicolumn{4}{|l|}{ Persistency* } \\
\hline$\leq 6$ months & 8 & 10 & 12 \\
\hline$>6$ months & 14 & 2 & 4 \\
\hline Glaucoma surgeries & $1.4 \pm 1.2$ & $1.6 \pm 1.0$ & $1.9 \pm 1.4$ \\
\hline
\end{tabular}

${ }^{\#}=$ mean intraocular pressure at presentation; ${ }^{*}=$ parameters with missing data

outcome studies, reporting worsening of the disease, reflect only a short-term follow-up. Kim et al., ${ }^{(16)}$ have shown, in the Advanced Glaucoma Intervention Study (AGIS), a 30\% mean worsening of the visual field in two years ${ }^{(17)}$. Few long-term studies have shown rates of worsening of about $81.4 \%$ over a 20 -year follow-up ${ }^{(14)}$.

We failed to find a perfect explanation for the higher proportion of patients who became bilaterally blind. Several possible factors may explain this proportion, including methodological inclusion criteria, such as the presence of a low proportion of patients initially not blind in group 3, and socioeconomic conditions. Besides, patients were selected from a referral glaucoma practice and may have differed in unknown ways from other populations of patients with glaucoma. Furthermore, a greater severity of disease at the time of diagnosis could also be associated with subsequent blindness.

Medical decisions in terms of changing an initial proposed therapy tend to be guided by clinical control of disease, economic aspects and health care provider, intensity of adverse effects, and marketing ${ }^{(16)}$. Moreover, persistency with the initial treatment results in reducing costs for both the patient and the health care system ${ }^{(1,17,18)}$. The multiplicity of options for glaucoma treatment and the difficulty in predicting the prognosis make it difficult to adopt a strategy that persists as desirable ${ }^{(19-21)}$. University hospitals work as referral centers for more complex cases of POAG and therefore one would predict that shorter persistency would be common ${ }^{(22-23)}$.

Most of the tertiary referral centers in ophthalmology in Brazil are part of the public health system, with universal access, free of cost to the patient and manage most of the POAG cases in the country. Compared to previous studies conducted at other tertiary hospitals in Brazil, our data revealed patients with similar initial characteristics ${ }^{(22-25)}$.

This study has demonstrated that low persistency with the initial therapy ( $\leq 6$ months) was the only significant risk factor for the development of both unilateral and bilateral blindness. Moreover, the multivariate analysis also revealed that the number of glaucoma surgeries was significantly related to bilateral blindness.

Although patients who experienced clinical worsening were more likely to discontinue the initial therapy within the first six months (unpublished data), it is possible that aggressive evolution of POAG was associated with an early change of medical decision about the initial prescription or vice-versa. It is also possible that patients with a more severe glaucoma onset required a greater number of surgeries in an attempt to control higher IOP levels.

This was a retrospective study, and the population analyzed is subject to several biases, other than those related to data collection mentioned above. Selection bias may exist in the types of patients who spontaneously seek or are referred to a university clinic. Most of the patients were treated by different ophthalmologists, and the results were subject to inconsistencies. Moreover, treatment profile could be related with persistency differences, once the number of topical medications available to treat POAG has increased since the beginning of the recruitment period. The weight of some other potential risk factors may also have been biased by missing data. Inclusion criteria could also bias the analysis due to the potential effect of lowering the mean age of patients at first clinic visit. In the present retrospective study, these weaknesses were accepted due to the improbability of drawing conclusions about the long-term follow-up of glaucoma in other circumstances.

Although the present findings indicate that the prognosis for patients diagnosed with POAG within the past 30 years may be considered disappointing as bilateral blindness from glaucoma was not uncommon, a further longitudinal study is needed to determine more accurately whether this conclusion is valid. Besides, our results also suggested that low persistency with the initial therapy and the number of glaucoma surgeries performed was the only significant factors associated with the development of blindness. However, in the clinical practice, these factors must be considered only in combination with other risk factors classically accepted in the literature.

\section{REFERENCES}

1. Heijl A, Leske MC, Bengtsson B, Hyman L, Bengtsson B, Hussein M; Early Manifest Glaucoma Trial Group. Reduction of intraocular pressure and glaucoma progression: Results from the early manifest glaucoma trial. Arch Ophthalmol. 2002;120(10): 1268-79. Comment in: Arch Opthalmol. 2002;120(10):1371-2; JAMA. 2002;288(20): 2607-8; Optom Vis Sci. 2002;79(121):741-2.

2. Van Buskirk EM, Cioffi GA. Glaucomatous optic neuropathy. Am J Ophthalmol. 1992; 113(4):447-52.

3. Quigley HA. Number of people with glaucoma worldwide. Br J Ophthalmol. 1996; 80(5):389-93

4. Schwartz GF. Persistency and tolerability of ocular hypotensive agents: populationbased evidence in the management of glaucoma. Am J Ophthalmol. 2004;137(1 Suppl): S1-2. Comment in: Am J Opthalmol. 2004;1093-4; author reply 1094.

5. Friedman DS, Hahn SR, Gelb L, Tan J, Shah SN, Kim EE, et al. Doctor-patient communication, health-related beliefs, and adherence in glaucoma results from the glaucoma adherence and persistency study. Ophthalmology. 2008;115(8):1320-7.

6. Quigley HA, Tielsch JM, Katz J, Sommer A. Rate of progression in open-angle glaucoma estimated from cross-sectional prevalence of visual field damage. Am J Ophthalmol. 1996; 122(3):355-63. Comment in: Am J Ophthalmol. 1997;123(3):426-8.

7. Hattenhauer MG, Johnson DH, Ing HH, Herman DC, Hodge DO, Yawn BP, et al. The probability of blindness from open-angle glaucoma. Ophthalmology. 1998; 105(11):2099-104. Comment in: Ophthalmology. 1999;106(11):2039-41. 
8. Shirakashi M, Iwata K, Sawaguchi S, Abe H, Nanba K. Intraocular pressure- dependent progression of visual field loss in advanced primary open-angle glaucoma: a 15-year follow-up. Ophthalmologica. 1993;207(1):1-5.

9. Zeyen TG, Caprioli J. Progression of disc and field damage in early glaucoma. Arch Ophthamol. 1993;111(1):62-5.

10. Arruda Mello PA, Mandia Jr C, editores. $2^{\circ}$ Consenso Brasileiro de Glaucoma Primário de Ângulo Aberto. São Paulo: PlanMark; 2005. p.12.

11. Anderson DR. Automated static perimetry. St. Louis: Mosby; 1992.

12. Chen PP. Correlation of visual field progression between eyes in patients with chronic open angle glaucoma. Ophthalmology 2002;109(11):2093-9.

13. Spaeth GL, Hwang S, Gomes M. Disc damage as a prognostic and therapeutic consideration in the management of patients with glaucoma. In: Gramer E, Grehn F, editors. Pathogenesis and risk factors of glaucoma. Berlin: Springer; 1999. p.135-44.

14. Eid TM, Spaeth GL, Bitterman A, Steinmann WC. Rate and amount of visual loss in 102 patients with open-angle glaucoma followed up for at least 15 years. Ophthalmology. 2003;110(5):900-7.

15. Chen PP. Blindness in patients with treated open-angle glaucoma. Ophthalmology. 2003:110(4):726-33. Comment in: Ophthalmology 2003:110(4):634-5.

16. Kim J, Dally LG, Ederer F, Gaasterland DE, VanVeldhuisen PC, Blackwell B, et al. The Advanced Glaucoma Intervention Study (AGIS): 14. Distinguishing progression of glaucoma from visual field fluctuations. Ophthalmology. 2004;111(11):2109-16.

17. Kobelt G, Jonsson L, Gerdtham U, Krieglstein GK. Direct costs of glaucoma ma- nagement following initiation of medical therapy. A simulation model based on an observational study of glaucoma treatment in Germany. Graefes Arch Clin Exp Ophthalmol. 1998;236(11):811-21

18. Florentinus SR, van Hulten R, Kloth ME, Heerdink ER, Griens AM, Leufkens HG, groenewegen PP; Netherlands Institute for Health Services Research. The effect of pharmacotherapy audit meetings on early new drug prescribing by general practitioners. Ann Pharmacother. 2007:41(12):319-24.

19. Taylor SA, Galbraith SM, Mills RP. Causes of non-compliance with drug regimens in glaucoma patients: a qualitative study. J Ocul Pharmacol Ther. 2002;18(5):401-9.

20 Realini T. Fechtner RD 56,000 ways to treat glaucoma. Ophthalmology 2002:109:1955-6.

21 Jönsson B. The health economics of glaucoma. In: Jönsson B, Kriegltstein G, editors. Primary open-angle glaucoma: differences in international treatment patterns and costs. Oxford: Isis Medical Media; 1999. p.1-9.

22. Grant WM, Burke JF Jr. Why do some people go blind from glaucoma? Ophthalmo logy. 1982:89(9):991-8.

23. Gullo RM, Costa VP, Bernardi L, Kara-José N. Visual conditions of glaucomatous patients in an university hospital. Arq Bras Oftalmol.1996;59(2):147-50.

24. Demarco AL, Rodrigues ML, Demarco LA. Ophthalmologic profile of patients going into the glaucoma wing of an university service. Medicina. 2002;35:478-86.

25. Oliveira A, Paranhos A Jr, Prata JA Jr. Characteristics presented by patients on their first appointment at the glaucoma sector of Universidade Federal de São Paulo - UNIFESP. Arq Bras Oftalmol. 2003;66(6):785-90.

\section{Congresso Norte-Nordeste \\ XIX Congresso Norte-Nordeste de Oftalmologia}

\section{1 a 23 de março de 2013}

\section{Enotel Resort \& SPA Porto de Galinhas}

Ipojuca (PE)

Informações:

Tel.: (81) 3033-5147

E-mail: secretaria.cnne2013@snno.com.br

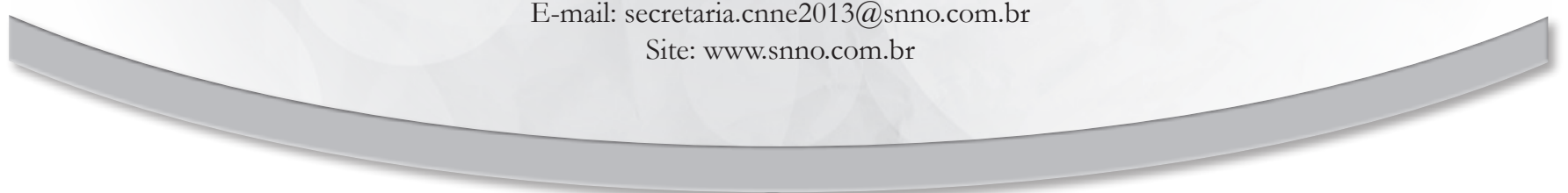

